\title{
COMPREHENSIVE MODEL OF PROTECTION AND RESCUE IN PRE- VENTIVE URBAN SECURITY
}

\begin{abstract}
In recent decades, the frequency of natural and anthropogenic accidents has increased worldwide. The large unplanned expansion of cities to accommodate rapid population growth, combined with unplanned field use and the failure of city governments to regulate building standards, contributes to the vulnerability of urban populations. The author attempts to point out the need to apply a comprehensive model of Protection and Rescue because current models and concepts are limited to the tasks that they theoretically conceptually include as well as the time phases in which they operate in the event of an accident. The solution is in the comprehensive Civil Defence Emergency Management Model, whose assessment of numerous accident risks relates to the process of identifying the occurrence, probability, and assumption of potential likelihood of different types of accidents within a general spatial and temporal framework of cities.
\end{abstract}

Keywords: ACCIDENTS, URBAN DEVELOPMENT, ACCIDENT PREPARATION, PROTECTION AND RESCUE, VULNERABILITY

\section{Introduction}

Technical and natural disasters are among the biggest threats faced by modern urban centres around the world. In a case of such present danger, the application of the activities, measures, forces and resources of the protection and rescue systems becomes an urgent priority. In this regard, countries are required to devote their attention to building efficient civil protection systems and to transform and refine the existing and such similar systems. Today such systems of civil protection occur in many forms, but it all comes down to the existence of similar concepts (such as the concepts of civil defence and crisis management).

In our case with the need for preventive solution for urban security problems, it seems logical that by defining and applying the physical elements of civil protection within the context of urban security plans and by creating a comprehensive preventive model of civil protection and crisis management strategies, the effect of potential accidents can be reduced. To this goal, we will first present an overview of the basic definitions and their theoretical implications in the field of protection and rescue and then focus our attention on the 
creation of a procedure for identifying the physical indicators that influence the usefulness of protection and rescue in the prevention phase of urban security.

\section{Accidents and accident management}

Accidents in modern urban centres can be a consequence of natural and technological phenomena and anthropogenic threats such as terrorism, bioterrorism, as well as the indirect effects of the use of chemical, biological, radiological and nuclear means. From this category of threats it should not be exclude the constant threat of infectious diseases. ${ }^{1}$ From an disaster management perspective (also known as emergency/accident management, or crisis management or incident management in narrow sense), it is applied science that attempts, through systematic accident monitoring and analysis, to found ways to prevent or mitigate their effects, create preparedness and assist rescue and relief operations, and direct disaster recovery. It is crucial to consider each of the stages of disaster management. There are generally four phases: mitigation, preparation, response, and recovery that all come together into two sets of activities, namely development planning and humanitarian activities (Warfield, 2008). The costs of ineffective or suboptimal disaster management at all stages of the disaster cycle (preparedness, mitigation, response, and recovery) are difficult to calculate, but are potentially excessive when consider excessive human suffering (Franco et al., 2007).

Given the current state of physical structures of cities, it would be better, in our attempt to combat technical and natural disasters, especially unpredictable ones, to focus on civil defense / civil protection rather than just disaster management which (though not entirely accurate) deals mainly with situations after the accident and damage control of such situations. In contrast to the primacy of the concept of civil defence/civil protection, by identifying preventive measures and properly assessment and prediction the values of relevant variables before an accident occurs we will be able to prevent or reduce the destruction caused primarily by natural disasters. Thus, we come to the need for a thorough discussion of civil defence.

\section{Civil Defence}

Civil defence in the second half of the last century was one of aspects of attack preparedness. Although its most ambitious elements, such as nuclear attack protection and rescue have never been fully implemented, civil defence techniques have gradually begun to gain wider relevance as they migrated to new areas of threat, such as natural disasters and industrial accidents. Unlike traditional terms, today, like many other terms, civil defence has several different connotations, and communication is often impossible when different mean-

\footnotetext{
${ }^{1}$ Such as avian influenza, severe respiratory syndrome (SARS), its successor - the new global virus COVID 19, and so on.
} 
ings without a specific contract of use are being used. Thus, while "civil protection" is a popular term in Europe, terms such as "disaster planning", "emergency management" and even "civil defence" are used in many other countries. There is considerable, but not complete overlapping between these different terms, though they are often used synonymously.

In view of the above discussion, a comprehensive understanding of civil defence can be presented whereby civil defence is a set of plans, actions and measures aimed to reduce the economic loss or loss of life of civilians in wars, or in technical and/or natural disasters such as earthquakes, floods, forest fires, droughts, winds, etc.

The development of protection and rescue in an organizational form of civil protection begins in the 1930s as a spontaneous attempt to organize civilians against the effects of air bombardment, such as in 1937 during the Spanish Civil War. This role became institutionalized during World War II, but its focus in the form of civil defence changed during the Cold War to the role where civilians prepare for atomic warfare (Alexander, 2006).

In the United States beginning in the early 1960s and with increasing momentum over the following decades (noticeable during the eighties and in most European countries), an alternative variant of readiness is being developed in parallel with the Federal Government's efforts to mobilize for nuclear war. State and local agencies have sought to use federal civil defence resources to prepare for and respond to natural disasters, i.e. extraordinary conditions (emergencies). Despite this different set of civil defence goals, the sphere of emergency preparedness was structured by the basic logic of civil defence: early disaster mobilization (Lakoff, 2007).

Since the end of the Cold War, the focus of civil defence has shifted greatly from military attack to emergency and disaster relief in general. Nationally, the civil defence system was developed earlier than all of today's similar security subsystems, such as a disaster planning, or emergency management system, or crisis management system. At the same time, locally, the main concern after World War II was disaster preparedness and response (Hilliard, 1986). So today, we can say that the methods and principles of civil defence are generally universally accepted, but that only the way they are implemented can vary according to the knowledge and skill of the decision makers and those to implement them. And precisely because the application of such principles of civil defence is flexible and varied, in the theory of classification of civil defence systems by their organizational form we distinguish between strictly organized civil defence systems and flexible organization civil defence systems (which is not so clearly visible).

Hence, in order to successfully carry out the tasks and activities of protection and rescue of civilians, there is a need to coordinate and unify existing protection and rescue systems (such as integrating the civil defence system with the crisis management system). The new concept of Civil defence emergency management or CDEM appears on the scene. Civil defence emergency manage- 
ment means: planning, organizing, coordinating and implementing the theory and practice of protection and rescue of people and material goods from hazards and consequences associated with any emergency that are necessary or desirable for public safety or safety of property; and are designed to protect, prevent, reduce or overcome any danger or damage or loss that may be associated with any emergency (The Ministry of New Zealand Civil Defense \& Emergency Management, 2008).

\section{Urban Security Through Strategic Planning of Civil Defence Management in Emergencies}

In order to reduce the damage caused during disasters, different and flexible urban plans in normal times are needed for cities to be prepared for natural disasters and to protect themselves against major damage and loss of life in other disasters. Implementing such plans can also facilitate post-disaster operations, environmental remediation and community recovery. The focus of CDEM should be to prevent disaster crisis by reducing vulnerability and risk. Vulnerability is a multidimensional approach and focuses on how society interacts with education, governance, values, laws, beliefs, and cultural practices in response to various dangers (Maha et al., 2008). In our specific case, the vulnerability to disaster in the physical structure of cities may be due to inadequate land use planning, lack of adequate infrastructure (transport network and urban installations), and non-compliance in urban materials and physical form (Imani et al., 2013, 77). Overall disaster preparedness, in addition to being a function of natural geographical conditions, and the position and physical characteristics of residential units, will be greatly enhanced by the special disaster response capabilities that need to be maintained through general training and specialized training for rescue and relief operations.

3.1. Indicators for preventive and mitigating measures of civil defence/protection prior to disaster occurrence in cities

\subsubsection{Vulnerability due to lack of proper land use planning:}

Land use planning is an attempt to reduce the number of conflicts and negative environmental impacts on society and nature. The main purpose of hazard-related land planning is to map the land, so that new development can be carried out beyond potentially hazardous sites. In this way, the damage caused to the physical elements of man and the social order, as well as to the environment is minimized.

A) First, the focus of attention should be on the functioning of the city. The functioning of the city is an indicator of the dominant economic activity in that city. The dominant economic activity in the city is a decisive factor in the creation of the predominant way of land use there. Basically, both from an economic and even physical perspective, the damage is more intense when the do- 
minant activity of the city is industrial rather than agricultural. But economic vulnerability can also be high where many businesses are of a non-productive type. (The International Bank for Reconstruction and Development, 2010).

B) Another important criterion is the type of land used. Some terrains used are more susceptible to earthquakes than others. For example, the terrain used for housing is more vulnerable than the terrain used for other purposes. Specific land uses such as plots allocated as public health centres, rescue and relief headquarters, school facilities etc. are in the second vulnerable group. The use of the terrain for military and official state purposes is subject to the least vulnerability, as such terrains are usually open. According to the UN Development Programme (UNDP) designated as Earthquake Risk Reduction and Recovery Preparation (ERRRP), this is because "open spaces in urban centres in several areas accessible to most of the population will be reserved for emergency evacuation. When reserving the ground as an open space, several lands will be identified for the immediate evacuation of certain communities and evacuation routes will also be identified in case of emergency "(Imani et al., 2013, 78).

C) Positioning land use in terms of geomorphologic value is another criterion to consider if vulnerability is to be reduced. Tectonic factors, such as distance from the lines of cleavage, land slope and soil composition are important factors that need to be taken into account when designating a particular land use.

D) Another important criterion is the proximity of the land used. This criterion should be respected in such a way that neighbouring land does not pose a threat in the event of scenarios resulting in the demolition/destruction of buildings. The risk increases when the adjacent land used is incompatible with form, space and activity, and decreases when land use is compatible in that respect.

E) The vulnerability of different land use is also determined by its time dependence. The more continuity in the functioning of the land is used, the more vulnerable it will be. Land use is divided into three categories in terms of the time-dependent risk. Land that is temporarily used non-stop, that is, with time dependence day and night is most vulnerable, such as houses and residential buildings that are at all times used for accommodation with the exception of those residential buildings that are used as a place to rest at night. Vulnerability to continuous, non-time-dependent land use, such as hospitals and police stations, which continuously perform the same function, varies depending on occupancy, construction quality and compliance with building standards. The least vulnerable are day-only properties, such as commercial property use, institutional and official property use.

F) The position of buildings in blocks can also affect their vulnerability. But this dependency is complex and variable in terms of the source of the threat. For example, individual parcels within a block have a different degree of vulnerability compared to similar parcels which are on the side of other plots 
or are in the middle, surrounded by other parcels in the event of an earthquake opposite to another threat such as flooding or a fire or a technical accident.

G) Vulnerability of buildings is one of the main factors affecting the occurrence of disaster victims. The physical characteristics of a building including age, façade materials, building materials, quality of construction, number of floors and type of construction are of prime importance in determining vulnerability. An important physical criterion is the occupancy rate (current occupation with people). The lower the occupancy rate, the less vulnerable the building will be. The value of this criterion comes down to the well-known relation between danger and resistance. So for example, no matter the magnitude of the hazard, if the resistance is high (in our case - minimum occupancy), the vulnerability remains small.

\subsubsection{Infrastructure-related vulnerability: urban installations and equipment, transport network}

Certain uses of property are crucial in determining overall vulnerability. These uses, collectively referred to as special use of property, include schools, universities, hospitals, rescue and relief centres, urban management centres, factories, fuel and chemical depots, and other hazardous materials, and so on.

Overall vulnerability is reduced if the transport network is capable of meeting the criteria for access to the property of special use. Availability of the transport network is essential for an efficient emergency response. This implies, in the context of planning, identifying critical routes that would remain operational after an accident to allow emergency response operatives to reach as many populations as possible in a minimal time (Srinivas et al., 2010).

Another criterion that relates to the transport network that is decisive in determining vulnerability is the degree of enclose. It is a function of the ratio of the width of the road and the height of the embankment.

The proximity of urban infrastructure/installations (excluding transport facilities) to residential and non-residential land can further exacerbate the damage caused by the disaster. Any of the installation networks such as gas, electricity, water supply, sewerage, and telecommunications are subject to damage. Such damage carries the primary consequences of the increased risk posed by the installation as well as the secondary consequences of malfunctioning or environmental pollution.

Apart from all this, the distribution and positioning of urban content / furniture (all necessary urban equipment distributed throughout the city, such as fire extinguishing pumps, report and alert centres, lamps, etc.) should contribute to reducing vulnerability and be suitable also for rescue and relief efforts.

\subsubsection{Vulnerability arising from urban form}

The urban physical form that is influenced by the main elements of the city and the relation between these elements is another decisive pathological 
indicator. Paying attention to criteria such as adherence to the proper hierarchical physical division of the city (in alleyways, neighbourhoods, districts and urban regions) is very important to reduce vulnerability. In general, discontinuous but orderly forms are less vulnerable to disasters.

Another important criterion is the way the city is expanded. Height expansion (vertical expansion) generally increases vulnerability.

\subsubsection{Vulnerability arising from urban materials}

The density of buildings and population, as well as the density of housing units, are among the decisive criteria for urban materials. As each of these densities increases, so does the vulnerability and likelihood of destruction. The population density, for example, is a criterion that determines the burden of population during a disaster. Accordingly, overcrowding with the city's population will result in a rapid decomposition of urban materials and installations and the imposition of pressure on settlements in the city that exceed their capacity to cope. A disaster will cause great human casualties due to the low resistance of buildings to high population density. Higher population density can slow down rescue operations or evacuation to shelters, while lower population density will have the opposite effect.

As another, also important criterion associated with the previous one is the parcel template. The geometric shape of the plots (neat and tidy) here is a standard for comparison, with three different models being respected: Neat, rectangular parcel templates; Regular, neat polygon patterns with very sharp or blunt angles; and Irregular and Combined templates/models. The first model reduces the overall vulnerability as it leaves more open space and is more efficient when it comes to providing shelter and temporary accommodation, than the last model which results in the highest overall vulnerability due to the inadequacy to provide shelter or access for rescuers. (Imani et al., 2013).

\section{Concluding observations - Efficiency of the Civil defence emergency man- agement model}

The model of Civil defence emergency management presented here, through the assumption/vision presented, explains the strategies for dealing with hazards. Given the importance of prevention prior to the disaster, a preventive strategy was presented in terms of physical indicators, criteria and measures in order to come up with a strategic plan for the Civil defence emergency management. A key feature of this planning model is the maintenance of support among all elements included in the IFACS. The extent of the damage from a particular disaster can be predicted if the vulnerability of that particular accident is well studied. The damage can be mitigated through effective planning before the disaster occurs and by implementing solutions inherent in the Civil defence emergency management template. In general, disaster mitigation can be achieved at the micro level first by compiling a map of vulnerability zones, 
taking the physical indicators of the Civil defence emergency management and their criteria into consideration and then presenting the goals and policies based on the risk areas and the stages of the Civil defence emergency management. Finally, comprehensive management of preventive plans can be achieved by an effective combinnation of detailed plans in the city.

\section{References:}

AleXANDer, D. (2006). 'Globalization of Disaster: Trends, Problems and Dilemmas', Journal of International Affairs, 59(2), 1-22. https://www.jstor.org/stable/24358424?seq=1\#metadata_info_tab_contents

FRANCO, C. \& DEITCH, S. (2007). 'Billions for Biodefense: Federal Agency Biodefense Funding, FY2007-FY2008', Journal of Biosecurity and Bioterrorism, $5(2), 17-33$.

HilliaRD, L. (1986). 'Local Government, Civil Defence and Emergency Planning: Heading for Disaster?', The Modern Law Review, Vol. 49, (4), 476-488.

IMANI, H. A., ZAHRA, S. S. Z., \& SARRAF, H. A. (2013). 'Integrating Civil Defense Emergency Management of Cities', International Journal of Architecture and Urban Development Vol. 3, No. 2, 75-86.

LAKOFF, A. (2007). 'Preparing for the Next Emergency', Journal of Public Culture, 19(2), 247-271.

MAHA, A. \& FRANZCISKA, G. (2010). 'Measuring Multidimensional Vulenrability in Afghanistan', Maastricht Graduate School of Governance, Working paper 2010004.

SRINIVAS, P., Sibel, F.S., DileK, G., \& KANNAN, V. (2010). 'Pre-disaster investment decisions for strengthening a highway network', Computers $\&$ Operations Research 37(10): 1708-1719.

THE INTERNATIONAL BANK FOR RECONSTRUCTION AND DEVELOPMENT. (2010). Natural Hazards, UnNatural Disasters: The Economics of Effective Prevention. The World Bank, Washington, DC.

The Ministry of New Zealand Civil Defence \& Emergency Management. (2008). National Civil Defense Emergency Management Strategy. https://www.ifrc.org/docs/idrl/235EN.pdf

WARFIELD, C. (2008). The Disaster Management Cycle.

https://www.gdrc.org/uem/disasters/1dm_cycle.html 